\title{
Substituição parcial e total do óleo de soja pelo óleo de tilápia em rações para larvas de tilápia do Nilo (Oreochromis niloticus)
}

\section{Partial and total substitution of soy oil for tilapia oil in rations for larvae of Nile tilapia (Oreochromis niloticus)}

\author{
Wilson Rogério Boscolo ${ }^{*}$; Arcangelo Augusto Signor ${ }^{2}$; Altevir Signor ${ }^{3}$; Aldi \\ Feiden ${ }^{4}$; Adilson Reidel ${ }^{5}$; Ronaldo José Boscolo ${ }^{6}$
}

\begin{abstract}
Resumo
O presente experimento teve por objetivo avaliar o desempenho e a sobrevivência da tilápia do Nilo (Oreochromis niloticus) na fase de reversão sexual, alimentadas com rações contendo diferentes níveis de inclusão de óleo de tilápia substituindo o óleo de soja. Foram utilizadas 375 larvas, com peso e comprimento médio de $0,012 \pm 0,002 \mathrm{~g}$ e $0,931 \pm 0,144 \mathrm{~cm}$, respectivamente, distribuídas em 25 aquários com 15 larvas em um delineamento inteiramente casualizado com 5 tratamentos e 5 repetições. As rações continham níveis de 0,$0 ; 2,5 ; 5,0 ; 7,5$ e 10,0\% de inclusão de óleo de tilápia, substituindo $100 \%$ do óleo de soja. As rações apresentavam $3.800 \mathrm{Kcal} / \mathrm{kg}$ de energia digestível e $38,6 \%$ de proteína digestível. Não foram observadas diferenças para o peso final, comprimento final, sobrevivência e fator de condição não apresentaram diferença. O óleo de tilápia pode substituir totalmente o óleo de soja para larvas de tilápia do Nilo durante a reversão sexual.
\end{abstract}

Palavras-chave: Desempenho, larvas, óleo de tilápia

\begin{abstract}
The present experimentwas undertaken out to evaluate the performance and the survival of Nile tilapia (Oreochromis niloticus) in the sexual reversion phase. The fish were fed with rations with different levels of tilapia oil in substitution of the soy oil. 375 larvae, with average weight of $0.012 \pm 0.002 \mathrm{~g}$ and lenght of $0.931 \pm 0.144 \mathrm{~cm}$, respectively were used. Fish were distributed in 25 aquariuns with 15 larvae in an entirely randomly design with 5 treatments and 5 repetitions. The rations contained levels of $0.0 ; 2.5 ; 5.0 ; 7.5$ and $10.0 \%$ of tilapia oil inclusion. Rations with $3.800 \mathrm{Kcal} / \mathrm{kg}$ of digestible energy and $38.6 \%$ of digestible protein were used. Differences for the final weight, final length, survival and condition factor were not observed. The tilapia oil can totaly substitute the soy oil in Nile tilapia larvae diets during sexual reversion.
\end{abstract}

Key words: Performance, larvae, tilapia oil.

1 Zootecnista; Professor Adjunto da Universidade Estadual do Oeste do Paraná - UNIOESTE, Rua da Faculdade 645, Jd. La Salle, Toledo-PR, CEP 85903-000. E-mail: wrboscolo@unioeste.br

2 Engenheiro de Pesca, Mestrando em Zootecnia - UNIOESTE/Marechal Candido do Rondon. E-mail: aasignor@pop.com.br.

3 Engenheiro de Pesca, Mestrado em Engenharia Agrícola - UNIOESTE/Cascavel. E-mail: acoldebella@uol.com.br

${ }^{4}$ Engenheiro Agrônomo; Professor Adjunto da Universidade Estadual do Oeste do Paraná - UNIOESTE. E-mail: aldi@unioeste.br

5 Engenheiro de Pesca, Doutorando em Aqüicultura - CAUNESP/Jaboticabal. E-mail: reidel@unioeste.br.

${ }^{6}$ Médico Veterinário. E-mail: rjboscolo@hotmail.com

" Autor para correspondência 


\section{Introdução}

As tilápias representam o segundo maior grupo de peixes mais cultivados mundialmente (BORGHETTI; OSTRENSKY; BORGHETTI, 2003). A espécie Oreochromis niloticus foi introduzida no Brasil em 1971, procedente da Costa do Marfim, África (CASTAGNOLLI, 1992). Essa espécie ocupa um baixo nível trófico (onívora) fato este que a coloca em vantagem em relação às espécies carnívoras que requerem grande quantidade de farinha de peixe nas rações (FITZSIMMONS, 2000; FOOD AND AGRICULTURE ORGANIZATION OF THE UNITED NATIONS - FAO, 2006).

Atualmente, as tilápias são industrializadas principalmente para a produção de filé, que corresponde aproximadamente a $35 \%$ da matériaprima total (SOUSA, 2002). Os 65\% restantes são compostos por vísceras, cabeças, nadadeiras, pele e espinha dorsal, formando um resíduo rico em proteínas e gorduras que geralmente são aproveitados para a produção de farinha de resíduos da indústria de filetagem (BOSCOLO et al., 2005a; 2005b). Devido ao alto teor de gordura que esses resíduos apresentam, o processo de produção de farinha exige um desengorduramento eficiente (ANDRIGUETO et al., 1984) para diminuir problemas como a peroxidação. Tais resíduos são cozidos em alta temperatura e pressão e, posteriormente, prensados, resultando em farinha e óleo. Os subprodutos apresentam excelente qualidade nutricional, podendo ser utilizados para a alimentação animal, além de apresentarem fácil disponibilidade no mercado, quando comparados a farinhas e óleos importados (SANCHES, 2004).

A utilização de lipídios na alimentação de peixes apresenta algumas vantagens, como fornecimento de energia de baixo custo (JUANCEY, 2000) e ácidos graxos essenciais (STEFFENS, 1987; NATIONAL RESEARCH COUNCIL - NRC, 1993). A utilização da gordura como fonte de energia varia conforme a espécie, dependendo de seu hábito alimentar, sendo que geralmente as rações para peixes carnívoros apresentam níveis mais elevados de gordura do que aquelas para onívoros e herbívoros (WILSON, 1998). El-Dahhar e El-Shazly (1993) e Chou e Shiau (1996) afirmaram que a tilápia não utiliza eficientemente os lipídios como fonte de energia quando este encontra-se acima de 5\% na ração. No entanto, Chou e Shiau (1996), observaram que 12\% de gordura na ração proporcionou o melhor ganho de peso para tilápias híbridas juvenis, por outro lado, as tilápias não toleram níveis tão altos de gordura quanto os salmonídeos (LOVELL, 1989) e Meurer, Boscolo e Hayashi (2002) afirma que 3,0\% de gordura na ração de alevinos de tilápia do Nilo proporcionou os melhores resultados.

Os óleos de origem vegetal são boas fontes de lipídios para peixes para alevinos de tilápia do Nilo (WILSON, 1995; HAYASHI et al., 2002), visto que o óleo de soja também pode ser substituído pelo óleo de tilápia para alevinos sem prejudicar o desempenho (SANCHES, 2004). No entanto, a qualidade da fonte de gordura utilizada na ração pode vir a influenciar significativamente no crescimento e conversão alimentar dos peixes (STICKNEY; MCGEACHIN, 1983).

No presente experimento, objetivou-se avaliar o desempenho e a sobrevivência de larvas de tilápia do Nilo durante a reversão sexual, alimentadas com rações, contendo diferentes níveis de inclusão de óleo de resíduos da indústria de filetagem de tilápias em substituição ao óleo de soja.

\section{Material e Métodos}

O experimento foi realizado no Laboratório de Aqüicultura da Universidade Estadual do Oeste do Paraná - UNIOESTE/Toledo, por um período de 24 dias. Foram utilizadas 375 larvas com dois dias pós a eclosão $(0,012 \pm 0,002 \mathrm{~g})$ e comprimento inicial médio $0,931 \pm 0,144 \mathrm{~cm}$. Foi utilizado o delineamento inteiramente casualizado com cinco tratamentos e cinco repetições, sendo a unidade experimental composta por um aquário de vidro de 30 L contendo 15 larvas. 
Os aquários possuíam aeração constante ligada por um sistema de mangueiras a um soprador de ar central, os quais foram sifonados diariamente pela manhã e à tarde, sendo que durante os treze primeiros dias a quantidade de água retirada foi igual a $25 \%$ do volume, e nos onze dias restantes $50 \%$ do volume a cada sifonagem. Os parâmetros físico-químicos da água como $\mathrm{pH}$, condutividade elétrica e oxigênio dissolvido foram mensurados semanalmente, enquanto que a temperatura foi monitorada diariamente de manhã $(8 \mathrm{~h})$ e à tarde (17h), antes da sifonagem.
Os alimentos foram moídos em um moinho tipo faca com peneira de $0,5 \mathrm{~mm}$ segundo Hayashi et al. (1999) e posteriormente, misturados os ingredientes secos e o óleo. As rações foram elaboradas de acordo com o NRC (1993) e Hayashi et al. (2002), sendo as mesmas isoenergéticas, isoprotéicas, isocálcicas e isofosfóricas. A inclusão do óleo de tilápia foi de 0,$0 ; 2,5 ; 5,0 ; 7,5$ e $10,0 \%$ substituindo-se $0 ; 25$; $50 ; 75$ e $100 \%$ de soja (Tabela 1). As rações foram fornecidas à vontade cinco vezes ao dia às $8 \mathrm{~h}$; 10h:30min; 13h; 15h:30min; 17h.

Tabela 1. Composição percentual e química das rações contendo diferentes níveis de inclusão de óleo de tilápia na alimentação de larvas de tilápia do Nilo.

\begin{tabular}{|c|c|c|c|c|c|}
\hline \multirow[b]{2}{*}{ Ingredientes } & \multicolumn{5}{|c|}{ Níveis de inclusão de óleo de tilápias (\%) } \\
\hline & 0,0 & 2,5 & 5,0 & 7,5 & 10,0 \\
\hline Farinha de vísceras de aves & 47,47 & 47,47 & 47,47 & 47,47 & 47,47 \\
\hline Farelo de soja & 32,88 & 32,88 & 32,88 & 32,88 & 32,88 \\
\hline Óleo de soja & 10,00 & 7,50 & 5,00 & 2,50 & 0,00 \\
\hline Óleo de tilápia & 0,00 & 2,50 & 5,00 & 7,50 & 10,00 \\
\hline Milho & 7,01 & 7,01 & 7,01 & 7,01 & 7,01 \\
\hline Fosfato bicálcico & 1,12 & 1,12 & 1,12 & 1,12 & 1,12 \\
\hline Suplemento (min.+vit.) $)^{1}$ & 1,00 & 1,00 & 1,00 & 1,00 & 1,00 \\
\hline Sal comum & 0,50 & 0,50 & 0,50 & 0,50 & 0,50 \\
\hline Antioxidante (BHT) & 0,02 & 0,02 & 0,02 & 0,02 & 0,02 \\
\hline Total & 100,00 & 100,00 & 100,00 & 100,00 & 100,00 \\
\hline \multicolumn{6}{|l|}{ Nutriente $\%$} \\
\hline Energia digestível $\mathrm{kcal} / \mathrm{kg}^{2}$ & 3800,00 & 3800,00 & 3800,00 & 3800,00 & 3800,00 \\
\hline Proteína bruta & 43,65 & 43,65 & 43,65 & 43,65 & 43,65 \\
\hline Proteína digestível $^{2}$ & 38,60 & 38,60 & 38,60 & 38,60 & 38,60 \\
\hline Lipídios & 20,42 & 20,45 & 20,47 & 20,49 & 20,51 \\
\hline Fibra bruta & 2,08 & 2,08 & 2,08 & 2,08 & 2,08 \\
\hline Cálcio & 1,38 & 1,38 & 1,38 & 1,38 & 1,38 \\
\hline Fósforo total & 1,03 & 1,03 & 1,03 & 1,03 & 1,03 \\
\hline Ácido linoléico & 7,36 & 6,32 & 5,28 & 4,24 & 3,19 \\
\hline Lisina & 2,09 & 2,09 & 2,09 & 2,09 & 2,09 \\
\hline Metionina & 0,57 & 0,57 & 0,57 & 0,57 & 0,57 \\
\hline Metionina + cistina & 2,04 & 2,04 & 2,04 & 2,04 & 2,04 \\
\hline
\end{tabular}

${ }^{1}$ Níveis de garantia por quilograma do produto: Vit. A, 500.000UI; Vit. $D_{3}, 200.000$ UI; Vit. E, 5.000 mg; Vit. K3, 1.000 mg; Vit. B1, 1.500 mg; Vit. B2, 1.500 mg; Vit. B6, 1.500 mg; Vit. B12, 4.000 mg; Ác. Fólico, 500 mg; Pantotenato Ca, 4.000 mg; Vit. C, 15.000 mg; Biotina, 50 mg; Inositol, 10.000; Nicotinamida, 7.000; Colina, 40.000 mg; Co, 10 mg; Cu, 500 mg; Fe, 5.000 mg; I, 50 mg; Mn, 1500 mg; Se, 10 mg; Zn,5.000 mg.

${ }^{2}$ Baseados nos valores de energia e digestível proposto por Boscolo, Hayashi e Meurer (2002). 
Ao final do período experimental, os peixes foram mantidos em jejum por 24 horas e, posteriormente, foram efetuadas as medidas individuais de peso (balança analítica) e comprimento total (equitiômetro). Foram avaliadas as médias de comprimento final (CF), peso final (PF), sobrevivência ( $\mathrm{SO}$ ) e fator de condição (FC) obtido através da expressão (wt/lt $\left.{ }^{3} \mathrm{x} 100\right)$, sendo $\mathrm{wt}=$ peso total e $1 \mathrm{t}=$ comprimento total, conforme descrito por Vazzoler e Vazzoler (1965).

Os dados das variáveis de peso final médio $(\mathrm{g})$, comprimento final médio $(\mathrm{cm})$, sobrevivência (\%) e fator de condição dos peixes de cada unidade experimental foram submetidos à análise de variância ao nível de $5 \%$ de significância pelo programa estatístico SAEG e em caso de diferença os dados foram comparados pelo teste de Tukey
$(\mathrm{P}<0,05)$ (Sistema de Análises Estatísticas $\mathrm{e}$ Genéticas) (UNIVERSIDADE FEDERAL DE VIÇOSA, 1997).

\section{Resultados e Discussão}

Os valores médios das variáveis físicas e químicas da água foram: $7,58 \pm 0,19, \quad 116,5 \pm 5,83 \mu \mathrm{S} / \mathrm{cm}$, $9,43 \pm 0,47 \mathrm{mg} / \mathrm{L}$ e $27,07 \pm 1,33^{\circ} \mathrm{C}$, respectivamente, para o $\mathrm{pH}$, condutividade elétrica, oxigênio dissolvido e temperatura. Os valores das variáveis estão dentro da faixa aceitável para a criação de peixes de clima tropical (BOYD, 1990; TAVARES, 1995).

Os dados de peso final médio, comprimento final, sobrevivência e fator de condição estão apresentados na Tabela 2 .

Tabela 2. Desempenho de larvas de tilápia do Nilo alimentadas com rações contendo diferentes níveis de inclusão de óleo de tilápia.

\begin{tabular}{lcccccc}
\hline \multirow{2}{*}{ Parâmetros* } & \multicolumn{5}{c}{ Níveis de inclusão de óleo de tilápia (\%) } & \multirow{2}{*}{ CV\% } \\
\cline { 2 - 6 } & 0,0 & 2,5 & 5,0 & 7,5 & 10,0 & \\
\hline Peso inicial (g) & $0,012 \pm 0,002$ & $0,012 \pm 0,002$ & $0,012 \pm 0,002$ & $0,012 \pm 0,002$ & $0,012 \pm 0,002$ & 16,66 \\
Peso final (g) & $0,83 \pm 0,19$ & $0,86 \pm 0,21$ & $0,80 \pm 0,12$ & $0,85 \pm 0,08$ & $0,93 \pm 0,15$ & 18,08 \\
Comprimento final (g) & $3,38 \pm 0,29$ & $3,87 \pm 1,16$ & $3,38 \pm 0,26$ & $3,36 \pm 0,14$ & $3,51 \pm 0,21$ & 16,33 \\
Sobrevivência (\%) & $82,66 \pm 10,11$ & $76,00 \pm 15,34$ & $61,66 \pm 21,39$ & $73,33 \pm 10,11$ & $72,00 \pm 12,76$ & 19,03 \\
Fator de condição & $2,14 \pm 0,18$ & $1,84 \pm 0,80$ & $2,10 \pm 0,24$ & $2,26 \pm 0,25$ & $2,14 \pm 0,13$ & 19,89 \\
\hline
\end{tabular}

* Não houve diferença estatística $(\mathrm{P}>0,05)$.

Nopresentetrabalhonãohouvediferença $(\mathrm{P}>0,05)$ entre as variáveis de peso final, comprimento final, sobrevivência e fator de condição. Resultados semelhantes, para as variáveis ganho de peso, peso da carcaça, sobrevivência, consumo alimentar e conversão alimentar aparente foram observados por Sanches (2004), que avaliou a substituição parcial e total do óleo de soja por óleo de vísceras de aves e óleo de tilápia para alevinos de tilápia do Nilo. Nwanna e Bolarinwa (2000), os quais avaliando diferentes óleos (soja, peixe marinho, palmeira e uma mistura de óleos vegetais) para alevinos de tilápia do Nilo, também não observaram diferenças no desempenho dos peixes.
Turchini et al. (2003) relataram não ter observado diferença no crescimento da truta marrom (Salmo truta) utilizando diferentes fontes de lipídios (óleo de peixe, canola, oliva, gordura de suínos e óleo de vísceras de aves). Resultados semelhantes onde não foram observadas diferenças no desempenho de peixes utilizando diferentes óleos, foram observados para Klinger, Blazer e Echevarria (1996), Caballero et al. (2002), Martino et al. (2002), Montero et al. (2003), Bendiksen, Arnesen e Jobling (2003) para o bagre do canal (Ictalurus punctatus), truta (Oncorhynchus mykiss), surubim (Pseudiplatystoma coruscans), truta (Sparus aurata) e salmon do Atlântico (Salmo salar L.). 
Os óleos e gorduras apresentam importantes funções metabólicas no organismo dos peixes, tendo em sua constituição altos níveis de energia (BOSCOLO; HAYASHI; MEURER, 2002). São excelentes fontes utilizadas na alimentação de peixes (STICKNEY; MCGEACHIN, 1983; WILSON, 1995). O óleo proveniente do processamento da tilápia pode ser utilizado como fonte energética na formulação de rações, sendo uma alternativa promissora para a indústria frigorífica. Atualmente, grandes quantidades de óleo de peixes são estocadas por longos períodos, levando à alta oxidação e, às vezes, até ao descartados, tornando-o um poluente ambiental.

Quanto à relação de ácidos graxos essenciais, a tilápia do Nilo apresenta uma exigência de 0,5\% de ácido linoléico (NRC, 1993). Nas rações deste experimento, verifica-se que, com o aumento da inclusão do óleo de tilápia, há uma diminuição dos teores de ácido linoléico, porém, com 100\% de substituição do óleo de soja pelo óleo de tilápia, o ácido linoléico permanece acima da exigência para a tilápia do Nilo.

\section{Conclusão}

O óleo de tilápia pode substituir totalmente $\mathrm{o}$ óleo de soja para larvas de tilápia do Nilo durante a reversão sexual.

\section{Agradecimentos}

Agradecemos ao apoio do Frigorífico Frigopisces de Bragantina - Assis Chateubriand, Estado do Paraná, pela doação do óleo utilizado neste experimento e à Aquacultura Tupi de Guairá, Estado do Paraná, pela doação das larvas utilizadas neste experimento.

\section{Referências}

ANDRIGUETO, J. M.; PERLI, L.; MINARDI, I.; FLEMMING, J. S.; GEMAEL, A.; SOUZA, G. A.; BONA FILHO, A. Nutrição Animal, São Paulo: Nobel, 1984. v. 2.

BENDIKSEN, E. A.; ARNESEN, A. M.; JOBLING, M. Effects of dietary fatty acid profile and fat content on smolting and seawater performance in Atlantic salmom (Salmo salar L.). Aquaculture, Amsterdam, v. 225, n. 14, p. 149-163, 2003.

BORGHETTI,N.R.B.; OSTRENSKY,A.;BORGHETTI, J. R. Aqüicultura: uma visão geral sobre a produção de organismos aquáticos no Brasil e no mundo. Curitiba: Grupo Integrado de Aqüicultura e Estudos Ambientais, 2003.

BOSCOLO, W. R.; HAYASHI, C.; MEURER, F. Digestibilidade aparente da energia e nutrientes de alimentos convencionais e alternativos para a tilápia do Nilo (Oreochromis niloticus, L.). Revista Brasileira de Zootecnia, Viçosa, v. 13, n. 2, p. 539-545, 2002.

BOSCOLO, W. R.; SIGNOR, A.; FEIDEN, A.; SIGNOR, A. A.; SCHAEFER, L. A.; REIDEL, A. Farinha de resíduos da indústria de filetagem de tilápias como fonte de proteína e minerais para alevinos de tilápia do Nilo (Oreochromis niloticus). Revista Brasileira de Zootecnia, Viçosa, v. 34, n. 5, p. 1425-1432, 2005a.

BOSCOLO, W.R; SIGNOR, A.; FEIDEN, A.; SIGNOR, A.A; SCHAEFER. L.A.; REIDEL, A. Farinha de resíduo da filetagem de tilápia em rações para alevinos de piavuçú, Leporinus macrocephalus. Revista Brasileira de Zootecnia, Viçosa, v. 34, n. 6, p. 1819-1827, 2005 b.

BOYD, C. Water quality in ponds for aquaculture. London: Birmingham Publishing, 1990.

CABALLERO, M. J.; OBACH, A.; ROSENLUND, G.; MONTERO, D.; GISVOLD, M.; IZQUIERDO, M. S. Inpact of different dietary sources on growth, lipid digestibility, tissue fatty acid composition and histplogy of rainbow trout (Oncorhynchus mykiss). Aquaculture, Amsterdam, v. 214, n. 1-4, p. 253-271, 2002.

CAStagnOLli, N. Piscicultura de água doce. Jaboticabal: Funep, 1992.

CHOU, B. S.; SHIAU, S. Y. Optimal dietary lipid level for growth of juvenile hybrid tilápia, Oreochromis niloticus x Oreochromis aureus. Aquaculture, Amsterdam, v. 143, n. 2, p. 185-195, 1996. 
EL-DAHHAR, A. A.; EL-SHAZLY, K. Effect of essential amino acids (methionine and lysine) and treated oil in fish diet on growth performance and feed utilization of Nile tilapia, Tilapia nilotica (L.). Aquaculture Fisheries Management, Campbell, v. 24, n. 6, p. 731-739, 1993.

FITZSIMMONS, K. Tilápia: most important aquaculture species of the $21^{\text {st }}$ century. In: INTERNATIONAL SYMPOSIUM ON TILÁPIA AQUACULTURE, 5., 2000, Rio de Janeiro, Anais... Rio de Janeiro: ISTA, 2000. p. 3-8.

FOOD AND AGRICULTURE ORGANIZATION OF THE UNITED NATIONS - FAO. The State of world aquaculture. Roma: FAO, 2006.

HAYASHI, C.; BOSCOLO, W. R.; SOARES, C. M.; BOSCOLO, V. R.; GALDIOLI, E. M. Uso de diferentes graus de moagem dos ingredientes em dietas para a tilápia do Nilo (Oreochromis niloticus L.) na fase de crescimento. Acta Scientiarum, Maringá, v. 21, n. 3, p. 733-737, 1999.

HAYASHI, C.; BOSCOLO, W. R.; SOARES, C. M.; MEURER, F. Exigência de proteína digestível para larvas de tilápia do Nilo (Oreochromis niloticus) durante a reversão sexual. Revista Brasileira de Zootecnia, Viçosa, v. 31, n. 2, p. 823-828, 2002.

JUANCEY, K. Nutritional requeriments. In: BEVERIDGE, M. C. M.; McANDREW, B. J. (Ed.). Tilapias: biology and exploitation. Stirling: Institute of Aquaculture - University Of Stirling, 2000. p. 327-375.

KLINGER, R. C.; BLAZER, V. S.; ECHEVARRIA, C. Effects of dietary lipid on the hematology og channel catfish, (Ictalurus punctatus). Aquaculture, Amsterdam, v. 73, n. 3-4, p. 225-233, 1996.

LOVELL, R. T. Nutrition and feeding of fish. New York: Van Nostrand Reinhold, 1989.

MARTINO, C. R.; CYRINO, J. E. P.; PORTZ, L. T.; TRUGO, L. C. Performance and fatty acid composition of surubim (Pseudiplatystoma coruscans) fed dietes with animal and plant lipids. Aquaculture, Amsterdam, v. 209, n. 1-4, p. 233-246, 2002.

MEURER, F.; BOSCOLO, W. R.; HAYASHI, C. Lipídios na alimentação de alevinos revertidos de tilápia do Nilo (Oreochromis niloticus, L.). Revista Brasileira de Zootecnia, Viçosa, v. 31, n. 2, p. 566-573, 2002.

MONTERO, D.; KALINOWSKI, T.; OBACH, A.; ROBAINA, L.; TORT, L.; CABALLERO, M. J.; IZQUIERDO, M. S. Vegetable lipid sources for giltheado seabream (Sparus aurata) effects on fish health. Aquaculture, Amsterdam, v. 225, n. 1-4, p. 353-370, 2003.

NATIONAL RESEARCH COUNCIL - NRC. Nutrient requeriments of fishes. Washington: National Academy Press, 1993.
NWANNA, L. C.; BOLARINWA, T. O. Effects of different dietary oils on the growth and economic performance of tilápia Oreochromis niloticus. In: TERNATIONAL SYMPOSIUM OF TILÁPIA AQUACULTURE, 5., 2000. Rio de Janeiro. Proeceedings... Rio de Janeiro: WAS, 2000. p. 227-234.

SANCHES, L. E. F. Substituição do óleo de soja por óleo de tilápia e óleo de vísceras de aves em rações para alevinos de tilápia do Nilo (Oreochromis niloticus). 2004. Tese (Doutorado em Zootecnia) - Universidade Estadual de Maringá, Maringá.

SOUSA, M. L. Comparação de seis métodos de filetagem, em relação ao rendimento de filé e de subprodutos do processamento da tilapia do Nilo (Oreochromis niloticus). Revista Brasileira de Zootecnia, Viçosa, v. 31, n. 3, p. 1076-1084, 2002.

STEFFENS, W. Princípios fundamentales de la alimentation de los peces. Zaragoza: Acribia, 1987.

STICKNEY, R. R.; MCGEACHIN, R. B. Effects of dietary lipid quality on growth and food convertion of tilápia. Proceedings of the Annual Conference Southeastern Association of Fish and Wildlife Agencies, Amsterdam, v. 37, p. 352-357, 1983.

TAVARES, L. H. S. Limnologia aplicada à aqüicultura. Jaboticabal: Funet, 1995.

TURCHINI，G. M.; MENTASTI，T.; FROYLAND, L.; ORBAN, E.; CAPRINO, F.; MORETTI, V. M.; VALFRE, F. Effects of alternative dietary lipid sources on perfornance, tissue chemical composition, mitochondrial fatty acid oxidation capabilities and sensory characteristics in brown trout (Salmo trutta L.). Aquaculture, Amsterdam, v. 225, n. 1, p. 251-267, 2003.

UNIVERSIDADE FEDERAL DE VIÇOSA. SAEG: sistema para análises estatísticas e genéticas: manual do usuário: versão 7.1. Viçosa: UFV, 1997.

VAZZOLER, A. E. A. M.; VAZZOLER, G. Relation between condiction factor and sexual development in Sardinella aurita. Anais da Academia Brasileira de Ciências, Rio de Janeiro, v. 37, p. 353-359, 1965. Suplemento.

WILSON, R. P. Lipid nutrition of finish: nutrition and utilization tecnology. In: LIM, C.; SESSA, D. J. (Ed.). Nutrition and utilization tecnology in aquaculture. Champaign: AOAC Press, 1995. p. 74-81.

WILSON, R. P. State of art of warmwater fish nutrition. In: SIMPÓSIO SUL AMERICANO DE AQUICULTURA, 1., 1998, Recife, CE. Anais... Florianópolis: SIMBRAQ, 1998. p. 375-380. 